\title{
RUSSIAN SYNTHETIC PINK QUARTZ
}

\author{
By Vladimir S. Balitsky, Irina B. Makhina, Vadim I. Prygov, Anatolii A. Mar'in, Alexandr G. Emel'chenko, \\ Emmanuel Fritsch, Shane F. McClure, Lu Taijing, Dino DeGhionno, John I. Koivula, and James E. Shigley
}

\begin{abstract}
Transparent crystals of facet-grade synthetic pink quartz, produced by bydrothermal growth from a fluoride solution and subsequent treatment, bave been commercially available since 1994. The characteristic properties that distinguish this material from its natural counterpart are a tabular crystal morphology with two large, well-developed basal faces; color bands parallel to the basal faces and the seed plate; two-phase inclusions adjacent and perpendicular to the seed plate; and an intense broad band around $3420 \mathrm{~cm}^{-1}$ in the infrared spectrum. Color stability and cause of color in synthetic pink quartz are briefly discussed.
\end{abstract}

The past few years have witnessed the appearance of a variety of synthetic gem materials from Russia, including synthetic emerald, spinel, opal, ruby, sapphire, and alexandrite. The production of transparent synthetic pink quartz in a Russian laboratory was first reported in 1992 (Balitsky et al., 1992, 1993; Makhina et al., 1992). The material has been commercially available since 1994, and is currently

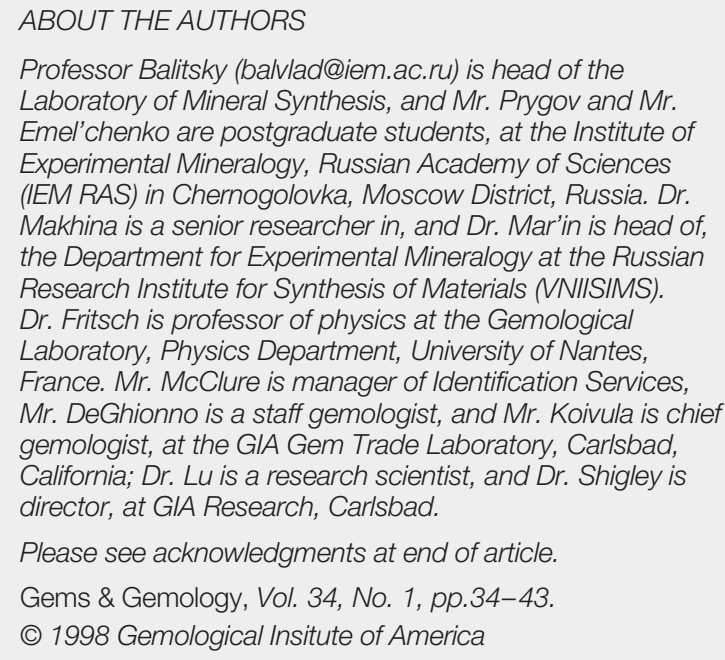

produced near Moscow at the Russian Research Institute for Synthesis of Materials. At present, production is $200 \mathrm{~kg}$ per year, in crystals measuring up to $150 \times 40 \times 20 \mathrm{~mm}$. This material (figure 1) is sold under the trade name "Flamingo Quartz" through HRI International Corp. of Midtown, New York.

The visible spectrum of this synthetic pink quartz is identical to that of natural transparent pink quartz (Rossman, 1994), and the growth conditions and cause of color are very similar (Balitsky et al., 1996). Therefore, we conducted a systematic investigation to establish gemological means to distinguish this new synthetic from its natural counterpart. This material and its natural equivalent will be referred to here as "pink quartz," to distinguish them from natural and synthetic "rose quartz."

\section{BACKGROUND}

Pink-colored quartz is found in nature in two forms: massive and crystalline. Massive "rose" quartz is relatively common in nature; it originates in granitic pegmatites together with large crystals of potassium feldspar, typically without other gem minerals (see, e.g., Frondel, 1962; Larson and Honert, 1977; Cassedanne and Cassedanne, 1978). This material inevitably appears slightly to very cloudy because of inclusions and its aggregate 
Figure 1. Transparent synthetic pink quartz is now being manufactured commercially in Russia.

These crystals (132.25-

$193.76 \mathrm{ct}$ ) and faceted samples (7.30-15.97 ct) of synthetic pink quartz are some of the samples used in this study. Photo by Maha DeMaggio.

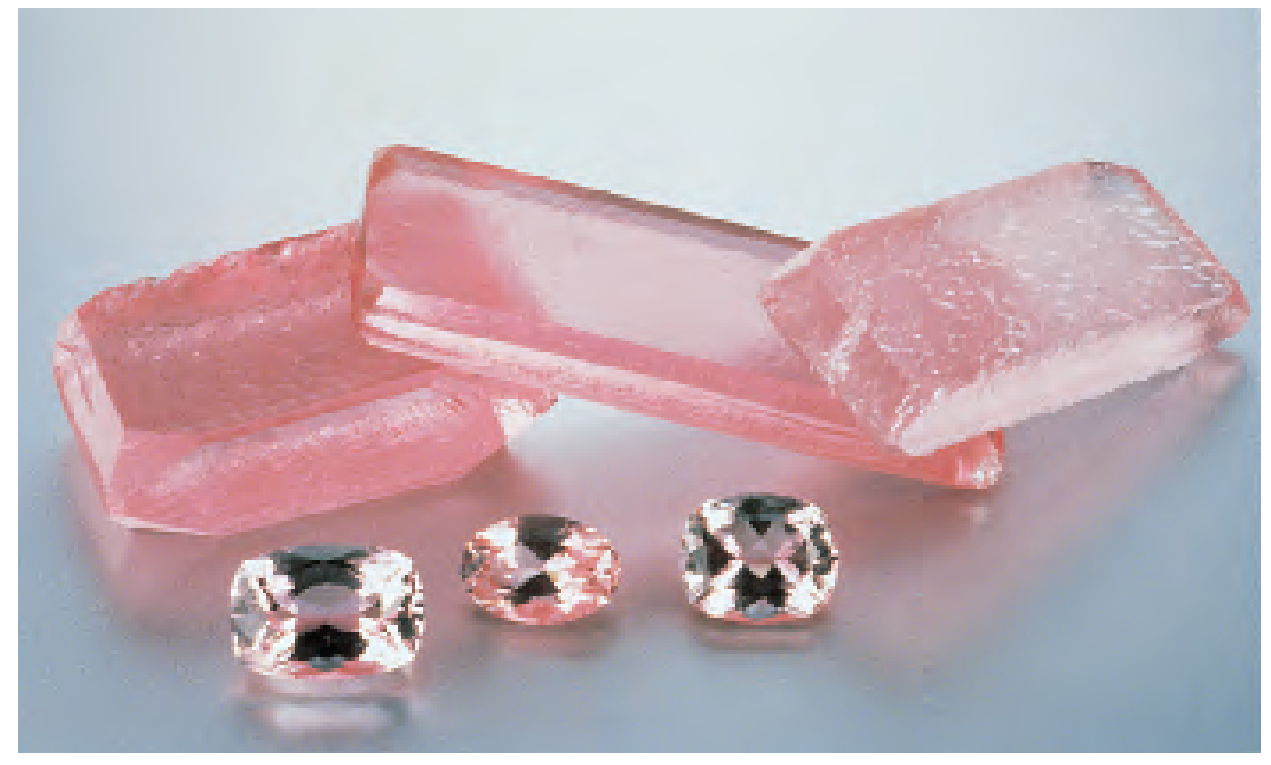

nature. Semi-transparent to translucent rose quartz can be polished as cabochons, some of which show asterism. Occasionally, rose quartz is even faceted.

Unlike massive rose quartz, transparent singlecrystal pink quartz is very uncommon in nature (see, e.g., Rossman, 1994). The crystals form in pockets toward the end of the granitic-pegmatite evolution process, often accompanied by gem tourmaline and phosphate minerals. Facetable material has been discovered in only two countries: Brazil (three deposits in Minas Gerais) and Madagascar (Maschmeyer and Lehmann, 1983; Cassedanne and Alves, 1990). In addition to its geologic formation, transparent pink quartz differs from massive rose quartz in terms of visible absorption spectra, stability to light, and origin of color (Balitsky et al., 1992; Rossman, 1994).

Typically, the crystals of natural pink quartz are small and available in limited supply. The only natural material encountered by GIA researchers in sizes large enough to yield $1+$ ct faceted stones is from the Araçuaí region of Minas Gerais (Kammerling and Fritsch, 1993); the Russian researchers have not encountered any faceted natural pink quartz outside of a museum in Russia. Although the samples examined to date are predominantly colorless, they have distinct planar bands or zones of intense pink color that can be oriented to give faceted stones an overall pink coloration when viewed table up.

Small (less than $3 \mathrm{~cm}$ ), thin crystals of semitransparent synthetic rose quartz have been produced in Japan, for research purposes only, since the mid-1980s. According to Hosaka et al. (1986), this material was grown hydrothermally from concentrated titanium-bearing alkaline solutions $(\mathrm{NaOH}$, $\mathrm{Na}_{2} \mathrm{CO}_{3}$, or $\mathrm{K}_{2} \mathrm{CO}_{3}$ ) in steel autoclaves at a temperature around $330^{\circ} \mathrm{C}$ and a pressure around $1 \mathrm{kbar}$. Plates of synthetic quartz cut parallel to the rhombohedral faces were used as seed crystals. The Japanese synthetic quartz was near-colorless in its as-grown state. The pink color was developed through subsequent heat treatment, which was carried out at $1200^{\circ} \mathrm{C}$ in a platinum crucible in which $\mathrm{CaCO}_{3}$ powder containing about $0.5 \mathrm{wt}$. $\%$ iron was used. The pink coloration has been attributed to a charge-transfer mechanism involving Ti-Fe ion pairs: The Ti was introduced into the quartz during growth, and the Fe was introduced during heat treatment. Hosaka et al. (1986) also state that the growth conditions and origin of color of this synthetic rose quartz are relatively close to those of natural massive rose quartz. However, the Russian product described here is the first commercially available transparent synthetic pink quartz.

\section{GROWTH AND IRRADIATION CONDITIONS}

The Russian synthetic pink quartz crystals are grown in steel autoclaves by a thermal-gradient hydrothermal method, from a solution containing ammonium fluoride $\left(\mathrm{NH}_{4} \mathrm{~F}\right)$ and silica (Balitsky and Tsinober, 1969; Balitsky et al., 1974, 1996). The autoclaves vary in volume from 300 to $500 \mathrm{ml}$. Phosphorus is added to the solutions in the form of either orthophosphoric acid or its salts. The growth temperature ranges from $220^{\circ}$ to $350^{\circ} \mathrm{C}$, and the pressure may attain $0.3 \mathrm{kbar}$. The interior of each autoclave is coated with a protective anticorrosion 
The visible-range spectra of all GIA samples were recorded with either a Hitachi U4001 or a PyeUnicam 8800 spectrophotometer. Polarized absorption effects were also investigated using the Hitachi spectrophotometer with a calcite polarizer. Infrared spectra were recorded for all rough and fashioned samples examined at GIA with a Nicolet Magna550 FTIR spectrometer.

Qualitative chemistry for all the GIA samples was obtained by energy-dispersive X-ray fluorescence (EDXRF) analysis with a Tracor Northern Spectrace TN 5000 system. Two sets of analytical conditions were used to detect as wide a range of trace elements as possible. Quantitative chemical analyses by electron microprobe were obtained on two of the four polished cubes of synthetic pink quartz; each had distinct color zoning, consisting of a pink layer and two colorless layers. The analyses were obtained using a JEOL Superprobe 733 instrument at the Division of Earth and Planetary Sciences, California Institute of Technology, Pasadena. The operating conditions were $20 \mathrm{kV}$ voltage, $100 \mathrm{nA}$ current, and a 600 second count time. The elements $\mathrm{P}, \mathrm{Al}, \mathrm{Fe}, \mathrm{Ti}, \mathrm{K}, \mathrm{Na}, \mathrm{Si}$, and $\mathrm{F}$ were analyzed to investigate the chemical composition of each layer and the cause of the pink color.

\section{RESULTS AND DISCUSSION}

Color and Color Distribution. The faceted synthetic samples ranged from light to medium-light pink (figure 3), while the synthetic crystals were medium pink (figure 4). The samples showed weak (rarely moderate) dichroism, in two tones of pink.

The coloration of the faceted synthetic pink quartz was uneven, in that it was confined to distinct pink bands that were visible in some samples without magnification. These bands were oriented parallel to the colorless synthetic quartz seed plate (figure 5). In some samples, the pink bands located farthest from the seed plate were darker than those nearer the seed plate.

The lighter-colored faceted samples were inert to the Chelsea filter (i.e., they appeared the same color as the filter); the deeper-colored faceted samples and the crystals showed a very weak reaction (i.e., they appeared slightly pink to orange-pink).

Crystal Morphology. All the crystals examined at GIA were euhedral single crystals. The well-developed basal surfaces were very rough, with abundant triangular growth hillocks (figure 6). The morphology of the synthetic pink quartz strongly depends

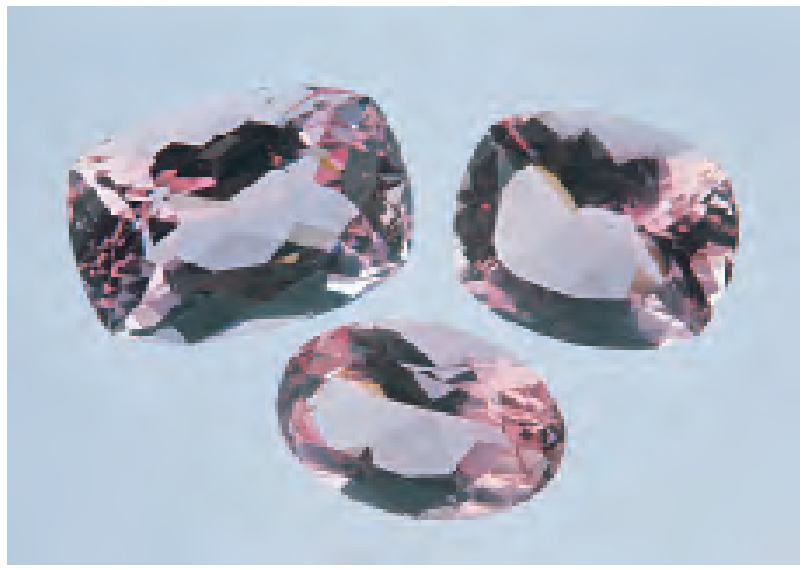

Figure 3. The faceted samples of synthetic pink quartz studied (here, 7.30-15.97 ct) ranged from light to medium-light pink. Photo by Maha DeMaggio.

on the shape of the seed plate and the relative growth rates of the major faces (Balitsky et al., 1992, 1993, 1996). Since rectangular seed plates elongated in either hexagonal (YZ-cut) or trigonal (XZ-cut) prism directions were used as seeds, and the growth rates of the major faces (except $c\{0001\}$ ) were very slow, the crystals have largely inherited the shape of the seed plate. Thus, all crystals were tabular. In addition to the well-developed basal $c$ faces, also present were smaller positive rhombohedral faces $r$ $\{10 \overline{1} 1\}$, negative rhombohedral faces $z\{01 \overline{1} 1\}$, hexag-

Figure 4. These synthetic pink quartz crystals (70-80 mm long and 10-18 mm thick) are representative of the samples studied in Russia and at GIA. Photo by Mikhail A. Bogomolov.

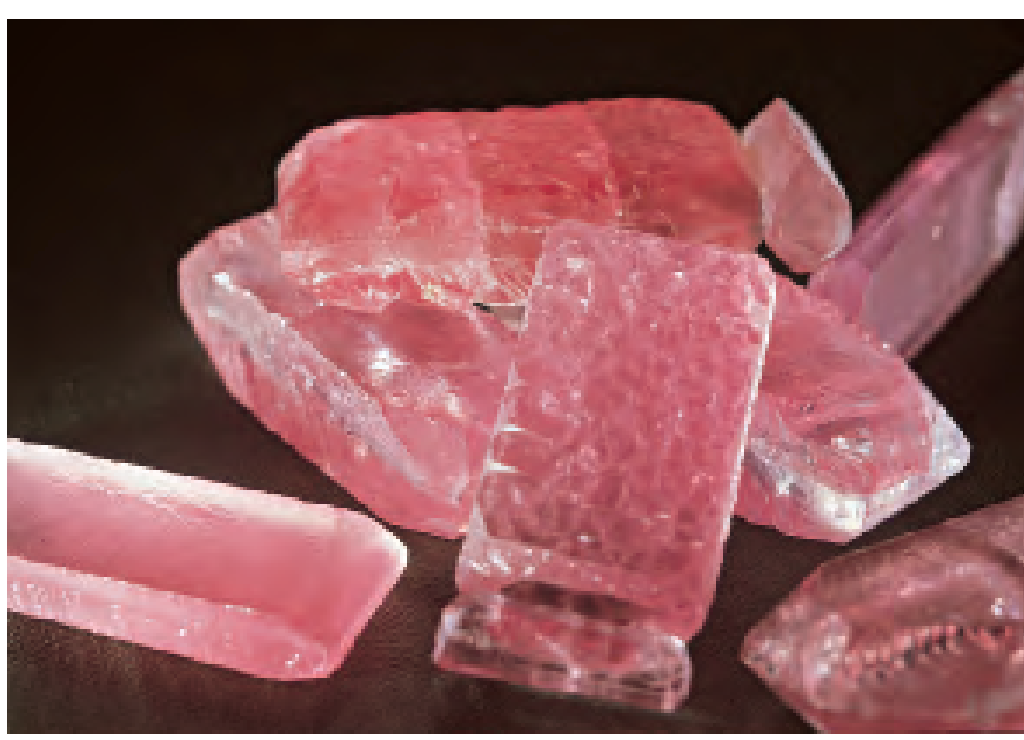




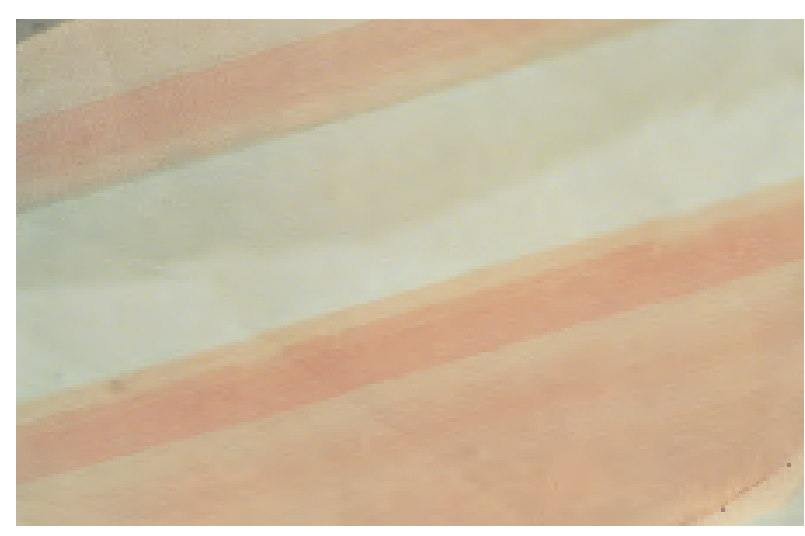

Figure 5. Prominent light to dark pink bands are visible in this faceted synthetic pink quartz. The color banding parallels the orientation of the colorless seed plate in the center. Photomicrograph by Shane F. McClure; immersed, diffused light, magnified $11 \times$.

Figure 6. Triangular growth hillocks are typically present on the basal c faces of Russian synthetic pink quartz crystals. Photomicrograph by Lu Taijing; magnified $7.5 \times$.

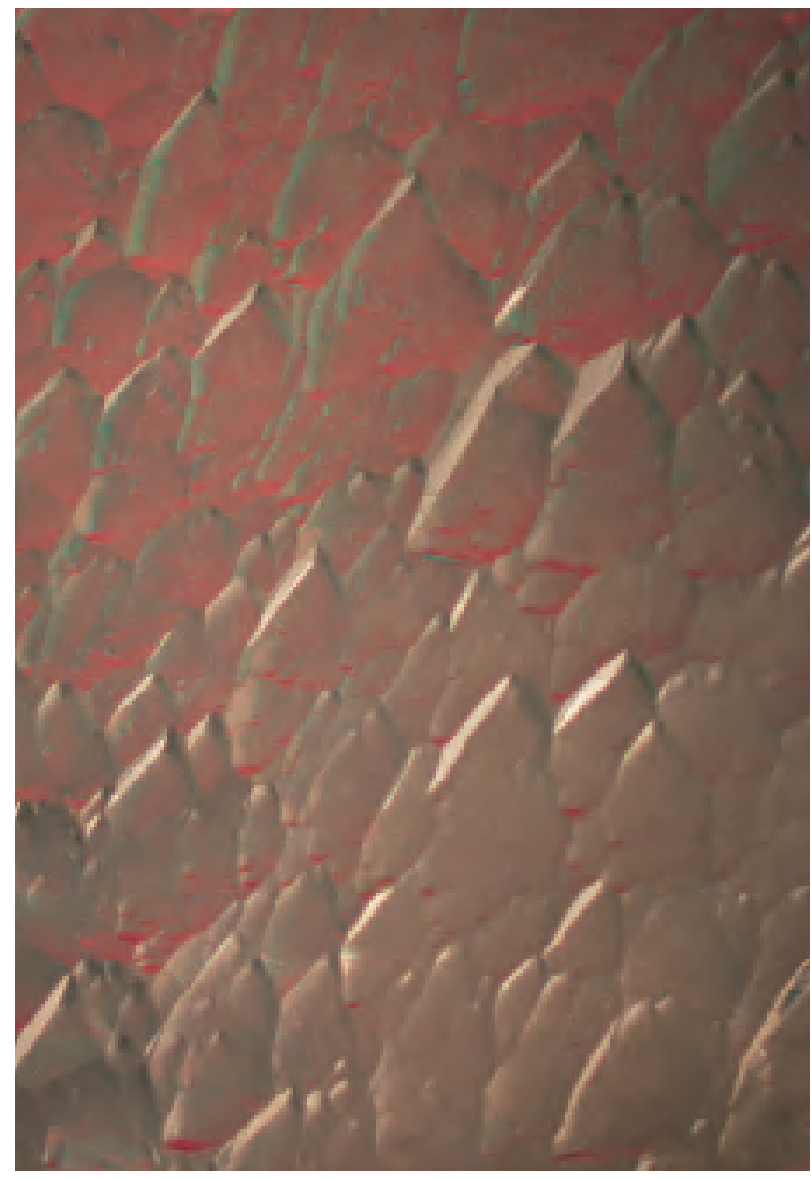

onal prism faces $m\{10 \overline{10} 0\}$, trigonal prism faces $+X$ $\{11 \overline{2} 0\}$ and $-x\{21 \overline{1} 0\}$, and trigonal dipyramid faces $+S$ $\{1 \overline{1} 1\}$ and $-s\{\overline{1} \overline{1} 21\}$. Figure 7 illustrates the crystal habits and the relationships between the seed plate and various growth sectors in the synthetic pink quartz. In comparison, natural crystals more commonly show a form with well-developed rhombohedral faces (Frondel, 1962).

Gemological Properties. Table 1 summarizes the gemological properties of the Russian synthetic pink quartz, as compared to natural pink quartz. The R.I., birefringence, and S.G. values are identical. All of the synthetic samples were inert to both longand short-wave UV radiation. In two of the crystals, however, we noted that the seed fluoresced a faint to weak yellow-green to both long- and short-wave UV.

Microscopic Characteristics. Color and Growth Zoning. As mentioned above, some of the specimens displayed eye-visible, straight, light and dark pink bands when viewed parallel to the plane of the seed plate. With magnification, we saw these bands in all the synthetic pink quartz samples (again, see figure 5). In some samples, the bands were extremely fine and closely spaced, whereas in others they were coarser and more distinct. Some additional, faint, parallel growth bands could be seen within the pink layers. The color bands, growth bands, and $c\{0001\}$ faces are parallel to one another (and, therefore, perpendicular to the optic axis). This suggests that the inhomogeneous color is caused by fluctuations in the growth conditions. In some specimens, the color bands were separated from one another by a plane showing a wave-like structure or appearance (figure 8). This feature has not been reported in the natural material.

Some samples displayed a stream-like structure that is typical of synthetic quartz grown in a fluorine-bearing solution (e.g., synthetic amethyst [Balitsky and Tsinober, 1969]). The stream-like structure is seen as faint lines that are oriented perpendicular to the color bands.

Although natural pink quartz also may display color bands and faint perpendicular stream-like structure lines (figure 9), orientation of these features in the two materials is different. In the natural material, the color bands are parallel to the rhombohedral faces (and therefore oblique to the optic axis), whereas in the synthetic material, the color bands are parallel to the basal faces (and therefore perpendicular to the optic axis). Also, the edges of color 
zones in natural pink quartz have a feathery appearance when viewed perpendicular to the direction of the color banding (figure 10). This feature is distinctive for natural material, and was not observed in any of the synthetic specimens.

Inclusions. Some of the synthetic pink quartz samples contained minute pinpoint and/or "breadcrumb" inclusions (figure 11), similar to those seen in other hydrothermal synthetic quartz (e.g., see figure 16 in Crowningshield et al., 1986). These inclusions were randomly distributed throughout the sample, or were concentrated along the contact of the seed crystal and the synthetic quartz over-

TABLE 1. Properties of Russian synthetic pink quartz as compared to natural pink quartz.

\begin{tabular}{|c|c|c|}
\hline Property & Synthetic & Natural \\
\hline Color & $\begin{array}{l}\text { Light to medium-light } \\
\text { pink }\end{array}$ & $\begin{array}{l}\text { Light to medium-light } \\
\text { pink }\end{array}$ \\
\hline Pleochroism & $\begin{array}{l}\text { Weak (rarely moderate) } \\
\text { dichroism in two tones } \\
\text { of pink }\end{array}$ & Weak \\
\hline R.I. $\left(n_{\omega}\right)$ & $1.540-1.541$ & $1.540-1.541$ \\
\hline R.I. $\left(n_{\varepsilon}\right)$ & 1.550 & 1.550 \\
\hline Birefringence & $0.009-0.010$ & $0.009-0.010$ \\
\hline S.G. & 2.65 & 2.65 \\
\hline Fluorescence & $\begin{array}{l}\text { Inert }{ }^{\text {a }} \text { to both long- } \\
\text { and short-wave UV }\end{array}$ & $\begin{array}{l}\text { Inert to both long- } \\
\text { and short-wave UV }\end{array}$ \\
\hline Optic character & Uniaxial positive & Uniaxial positive \\
\hline Twinning & None observed & $\begin{array}{l}\text { Brazil-law twinning in } \\
\text { all samples }\end{array}$ \\
\hline $\begin{array}{l}\text { Visible } \\
\text { absorption } \\
\text { spectrum }\end{array}$ & Band near 520 nm & Band near 520 nm \\
\hline $\begin{array}{l}\text { IR absorption } \\
\text { spectrum }\end{array}$ & $\begin{array}{l}\text { Broad band near } \\
3420 \mathrm{~cm}^{-1}\end{array}$ & $\begin{array}{l}\text { Sharp, intense } \\
\text { band at about } 3580 \\
\mathrm{~cm}^{-1} ; \text { broad peak } \\
\text { at } 3415 \mathrm{~cm}^{-1}\end{array}$ \\
\hline $\begin{array}{l}\text { Color and } \\
\text { growth zoning }\end{array}$ & $\begin{array}{l}\text { Color bands parallel } \\
\text { to basal faces } \\
\text { (and seed plate), } \\
\text { perpendicular to the } \\
\text { optic axis; wave- and } \\
\text { stream-like structures }\end{array}$ & $\begin{array}{l}\text { Color bands parallel } \\
\text { to rhombohedral } \\
\text { faces, oblique } \\
\text { to the optic axis; } \\
\text { feathery appearance } \\
\text { at the edges }\end{array}$ \\
\hline Inclusions & $\begin{array}{l}\text { Breadcrumb inclusions; } \\
\text { elongate two-phase } \\
\text { (liquid-gas) inclusions } \\
\text { confined to a colorless } \\
\text { seed plate }\end{array}$ & $\begin{array}{l}\text { Liquid and two-phase } \\
\text { (liquid-gas) inclusions } \\
\text { in curved planes } \\
\text { that cross the color } \\
\text { bands at random } \\
\text { angles }\end{array}$ \\
\hline
\end{tabular}

aThe synthetic quartz seed plate sometimes fluoresces a faint to weak yellow-green to both long- and short-wave UV.
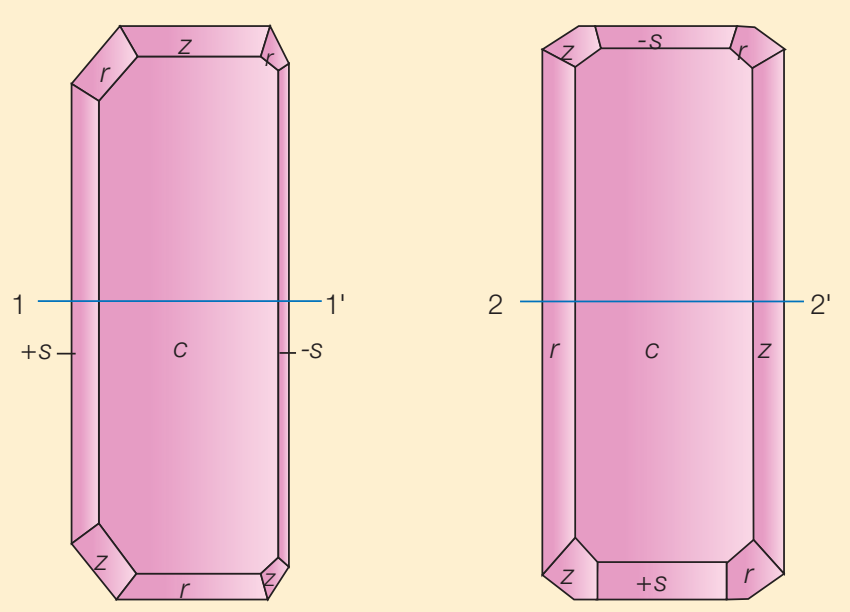

YZ-cut seed

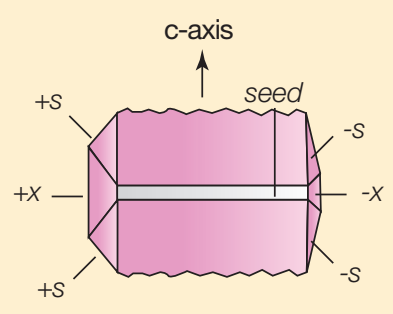

Section $11^{\prime}$

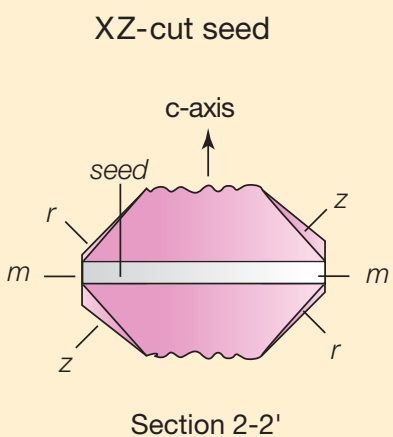

Section 2-2'

Figure 7. The Russian synthetic pink quartz crystals studied revealed two variations in the tabular crystal habit, depending on the type of seed plate used (YZ-cut or XZ-cut).

Figure 8. A wave-like appearance is visible on the planar surface between color bands in this $7.30 \mathrm{ct}$ faceted synthetic pink quartz. The blue color is due to diffraction of light through the stone. Photomicrograph by Shane F. McClure; magnified 40×.

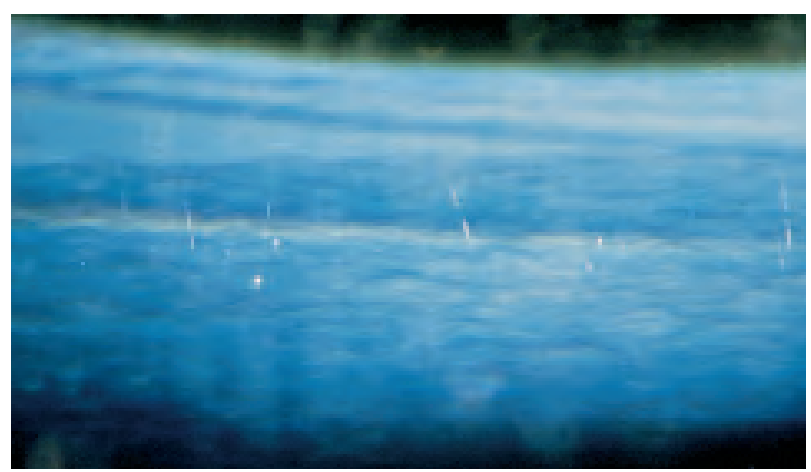



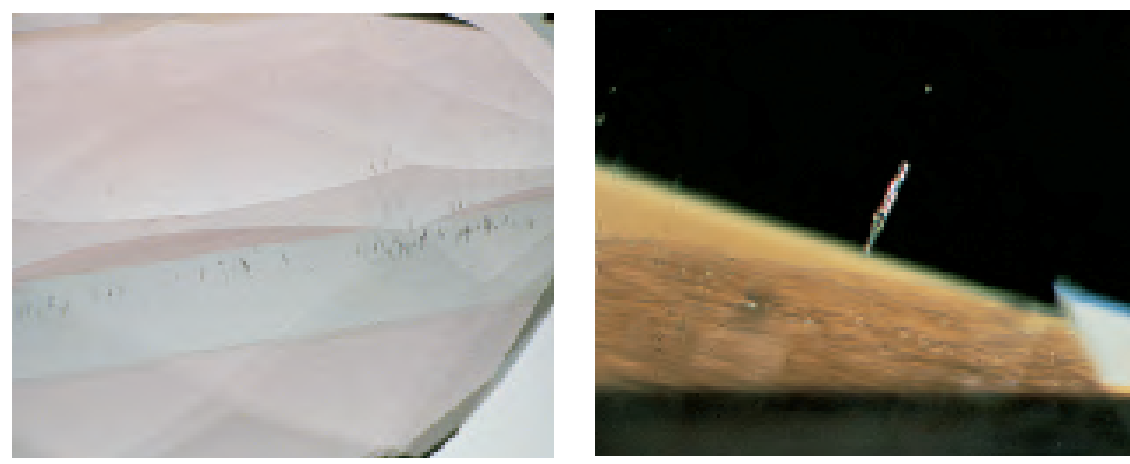

Figure 12. Elongate two-phase inclusions were seen in flat planes confined to the seed plate in some samples (left). These inclusions were always perpendicular to the seed plate, and commonly appeared spike-shaped (right). Photomicrographs by Shane F. McClure; magnified 10× (left) and $28 \times$ (right).

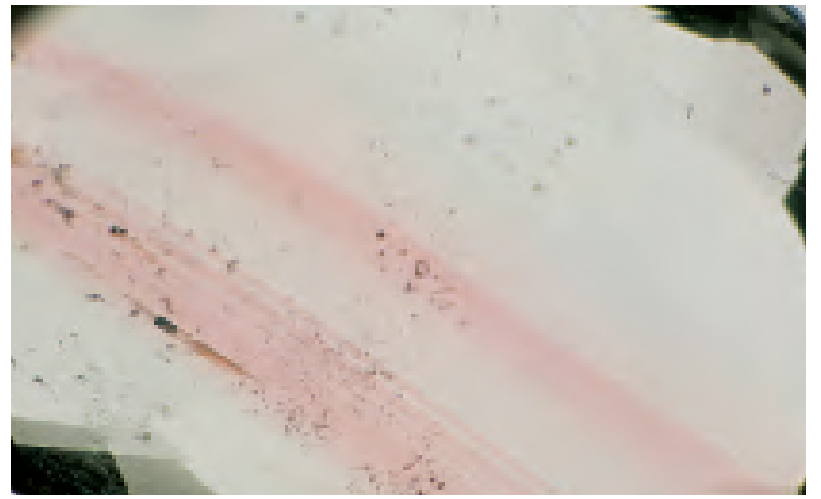

Figure 13. Curved planes of liquid and two-phase inclusions crossed the pink color bands at random angles in this natural pink quartz from Brazil. Photomicrograph by Shane F. McClure; magnified $10 \times$.

plays a sharp, intense peak at $3587 \mathrm{~cm}^{-1}$, a small peak at $3542 \mathrm{~cm}^{-1}$, and a broader peak at $3415 \mathrm{~cm}^{-1}$. In contrast, the synthetic sample exhibits a broad absorption feature centered at $3420 \mathrm{~cm}^{-1}$, and weaker features between 3500 and $3650 \mathrm{~cm}^{-1}$.

The broad band at about $3420 \mathrm{~cm}^{-1}$ is due to molecular $\mathrm{H}_{2} \mathrm{O}$ (Rossman, 1988); the tiny peaks at $3607 \mathrm{~cm}^{-1}, 3572 \mathrm{~cm}^{-1}$, and $3542 \mathrm{~cm}^{-1}$ may be related to structural fluorine-hydrogen complexes (Balitsky et al., 1974). By comparison, the intense peak at $3587 \mathrm{~cm}^{-1}$ and the broad peak at $3415 \mathrm{~cm}^{-1}$ in the natural material are due to hydroxyl group stretching vibrations (Katz, 1962; Rossman, 1988). These differences suggest that synthetic pink quartz contains relatively more molecular water than the natural material.

Chemical Composition. EDXRF analysis revealed potassium, iron, calcium, and chromium in both rough and fashioned samples of the synthetic pink quartz. Electron microprobe analysis of the two polished cubes revealed phosphorus $(\mathrm{P})$ and potassium
(K) as the main trace elements. The concentrations of phosphorus and potassium in the dark pink band (P: 390 ppm [parts per million], K: 270 ppm) were much higher than in the light pink band (P: 140 ppm, K: $20 \mathrm{ppm}$ ) of the same sample. The concentration of sodium $(\mathrm{Na})$ was much lower than that of potassium (Na: $10 \mathrm{ppm}, \mathrm{K}: 270 \mathrm{ppm}$ ) in the dark pink layer. Aluminum, iron, titanium, and fluorine were not detected by microprobe in either sample.

Cause of Color. The high concentrations of phosphorus and potassium in the pink bands suggest that these elements are related to the coloration of synthetic pink quartz. In particular, it is believed that phosphorus-which is added to the growth solution-plays a very important role (Balitsky et al., 1993, 1996). This is supported by chemical data

Figure 14. These visible absorption spectra were recorded using polarized light for orientations parallel (II) and perpendicular $(\perp)$ to the optic axis (caxis) of the synthetic pink quartz. The two spectra are not scaled vertically with respect to one another. The $520 \mathrm{~nm}$ broad band is more intense in the spectrum that is perpendicular to the optic axis. Increasing absorption below $400 \mathrm{~nm}$ is visible in both spectra.

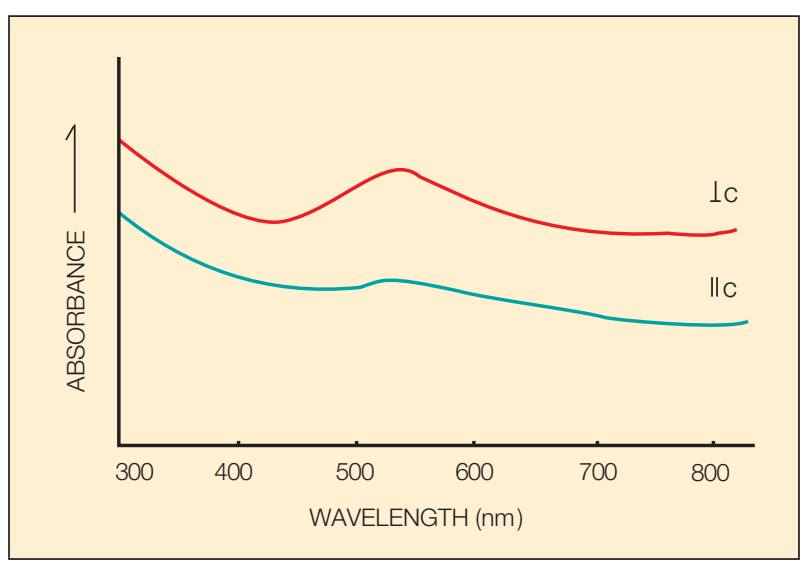


presented here and by electron paramagnetic resonance spectra on synthetic quartz from Russia (Maschmeyer and Lehmann, 1983; Rossman, 1994). Ionizing radiation can produce a complex color center from phosphorus and/or other elements present. This complex center is probably the origin of the color in the synthetic pink quartz, but its details and the coloration mechanism remain to be investigated.

Color Stability. Within two weeks of gamma-ray irradiation, up to $15 \%$ of the pink color fades under normal lighting conditions (i.e., the material retains about $85 \%$ of its original color). After this period, however, the color stabilizes, as was evident by comparison of the samples exposed to sunlight for three years (see, e.g., the smaller piece in figure 16,

Figure 15. Note the differences between these representative infrared absorption spectra for a natural pink quartz from Brazil (A) and a Russian synthetic pink quartz (B) above 3000 $\mathrm{cm}^{-1}$. In particular, the synthetic pink quartz shows an intense broad band at $3420 \mathrm{~cm}^{-1}$.

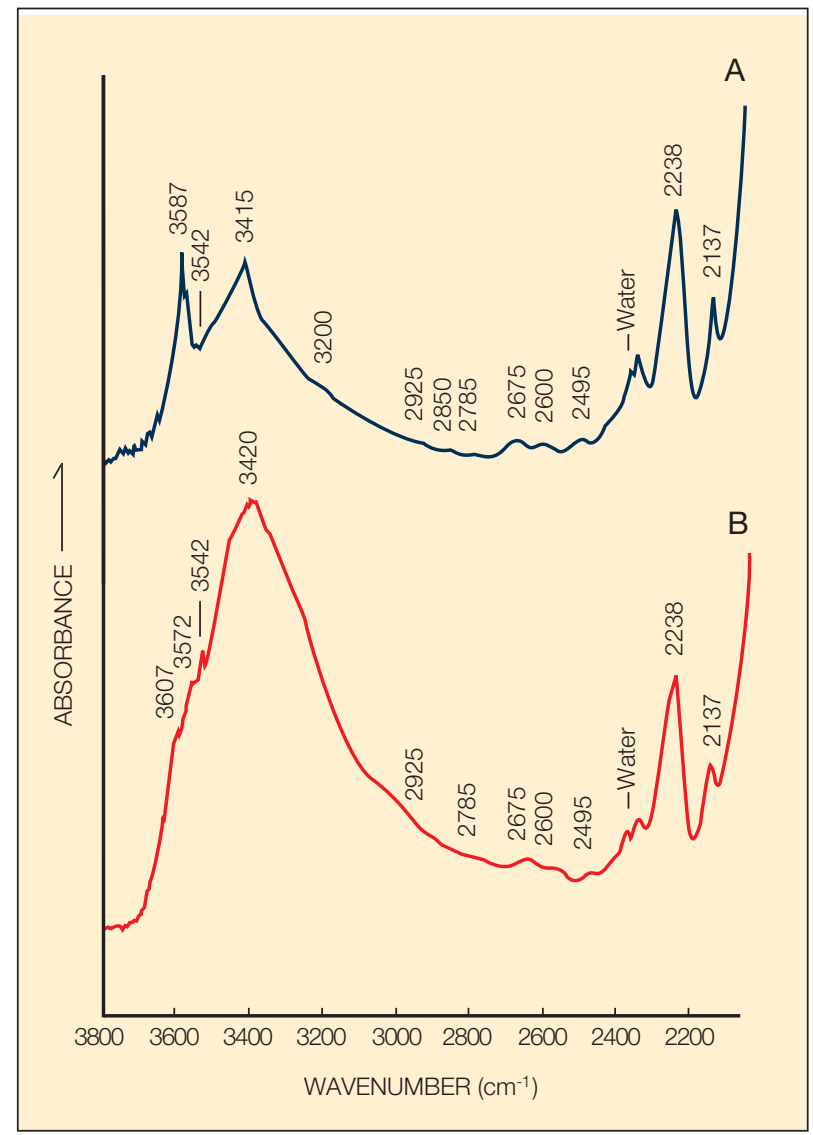

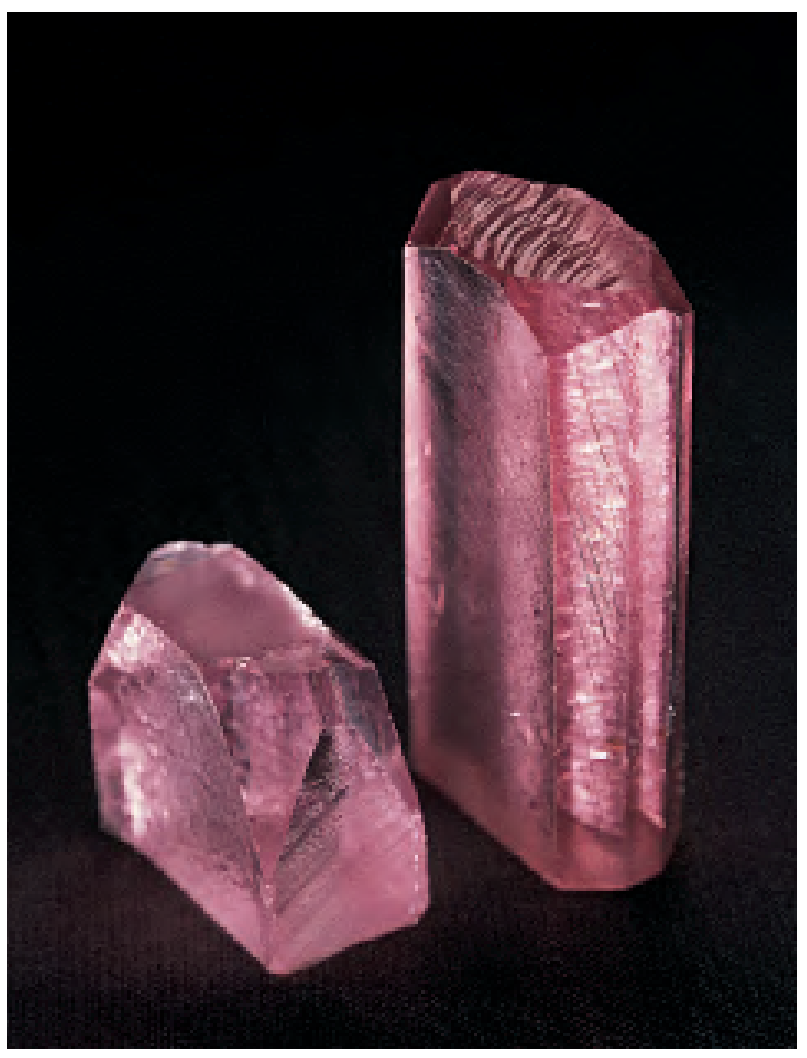

Figure 16. These two samples of synthetic pink quartz are shown here three years after they were irradiated, at which time they were both the same color. However, the crystal on the right $152 \mathrm{~mm}$ long $\times 10 \mathrm{~mm}$ thick) was kept in the dark for the three years, whereas the crystal segment on the left (23 mm long and $12 \mathrm{~mm}$ thick) was one of several that were exposed to sunlight throughout this period. The fact that there is very little difference in color between the two samples indicates that the color appears to be stable over time. Photo by Mikhail A. Bogomolov.

on the left) to the control sample kept in the dark for the same period (the larger crystal in figure 16). Color stability was maintained at temperatures below $180^{\circ}-200^{\circ} \mathrm{C}$, but above this range the color disappeared quickly. However, the color could be fully restored by irradiation if the material was not heated above about $350^{\circ} \mathrm{C}$, and could be partially restored if it was not heated above $450^{\circ} \mathrm{C}$; above $500^{\circ} \mathrm{C}$, the color could not be restored.

\section{CONCLUSION}

Although there are many similarities between natural pink quartz and synthetic hydrothermal pink 
quartz grown in Russia, we found sufficient differences between the samples we examined to allow separation by standard gem-testing methods. Advanced testing techniques provide supporting evidence for this separation. The synthetic crystals display a characteristic tabular morphology with two large, well-developed basal faces. Color bands are always parallel to the basal faces (and perpendicular to the optic axis) in the synthetic pink quartz, whereas the color bands are always parallel to the rhombohedral faces (and oblique to the optic axis) in the natural pink quartz. The color zones in the natural material showed feathery edges when observed perpendicular to the banding, which were not seen in the synthetics. Small, elongate two-phase inclusions are sometimes seen within and perpendicular to the seed. Curved planes of liquid and two-phase inclusions that crossed the parallel color banding were only seen in the natural material. Unlike most natural material, all of the synthetic pink quartz we examined lacked twinning.

The intense broad band at about $3420 \mathrm{~cm}^{-1}$ in the infrared absorption spectrum of synthetic pink quartz conclusively separates this material from its natural counterpart. The pink color is thought to result from a phosphorus-related complex color center created by ionizing radiation.

Currently, about $200 \mathrm{~kg}$ of this material is produced annually, in crystals up to $150 \times 40 \times 20 \mathrm{~mm}$. Production capacity could be significantly increased if warranted by market demand.

Acknowledgments: The authors thank Jerry Romanella of Commercial Mineral Company, Scottsdale, Arizona, for donating samples of natural, color-zoned pink quartz from Araçuai, Brazil. The late R. C. Kammerling, of the GIA Gem Trade Laboratory, made contributions to earlier versions of this manuscript. Sam Muhlmeister of GIA Research prepared the EDXRF spectra. Dijon Douphner, formerly of the GIA Gem Trade Laboratory, prepared the infrared absorption spectra. Paul Carpenter, of the California Institute of Technology, carried out the electron microprobe analysis. Drs. Ilene Reinitz and Mary Johnson of the GIA Gem Trade Laboratory made useful comments on the original manuscript. This study was supported by a grant (97-05-64805) from the Russian Basic Research Foundation.

\section{REFERENCES}

Balitsky V.S., Tsinober L.I. (1969) Some peculiarities of quartz recrystallization from fluoride-bearing hydrothermal solutions. Doklady Akademii Nauk SSSR, Vol. 187, No. 5, pp. 1142-1145 (in Russian).

Balitsky V.S., Makhina I.B., Tsinober L.I. (1974) About the presence of fluoride impurities in synthetic quartz crystals. Geokhimiya, Vol. 3, pp. 487-491 (in Russian).

Balitsky V.S., Makhina I.B., Prygov V.I. (1992) Proceedings on quartz mineralogy: Created rose quartz. Komi Institute of Geology, Ural Scientific Center of the Russian Academy of Sciences, Syktyvkar. pp. 65-66 (in Russian).

Balitsky V.S., Makhina I.B., Prygov V.I., Mar'in A.A. (1993) Manmade rose quartz. Proceedings, 24th International Gemological Conference, 12-15 October 1993, Paris, France.

Balitsky V.S., Makhina I.B., Emel'chenko A., Mar'in A.A., Shigley J., Fritsch E., Koivula J. (1996) Formation of rose phosphorous-bearing quartz and causes of its rarity in nature: An experimental study. Geokhimiya, Vol. 34, No. 11, pp. 1074-1081 (in Russian).

Cassedanne J.-P., Cassedanne J.-O. (1978) La pegmatite o quartz rose du Alto Feio. Revue de Gemmologie a.f.g., No. 57, pp. $11-14$.

Cassedanne J.-P., Alves J. (1990) Crystallized rose quartz from Alto da Pitora, Minas Gerais, Brazil. Mineralogical Record, Vol. 21, No. 5, pp. 409-412.

Crowningshield R., Hurlbut C., Fryer C.W. (1986) A simple procedure to separate natural from synthetic amethyst on the basis of twinning. Gems ↔) Gemology, Vol. 22, No. 3, pp. $130-139$.

Frondel C. (1962) Dana's System of Mineralogy, 7th ed., Vol. 3 , Silica Minerals. John Wiley \& Sons, New York.

Hosaka M., Miyata R., Shimizu Y., Okuyama O. (1986) Synthesis of rose-quartz crystal. Journal of Crystal Growth, Vol. 78, pp. 561-562.

Kammerling R.C., Fritsch E. (1993) Gem trade lab notes: Colorzoned pink quartz. Gems $\oplus$ Gemology, Vol. 29, No. 3, pp. 203-204.

Katz A. (1962) Hydrogen in alpha-quartz. Philips Research Reports. Vol. 17, No. 1-2, pp. 133-168.

Larson P., Honert J. (1977) Rose quartz of the Black Hills. Lapidary Journal, Vol. 31, No. 2, pp. 534-538.

Makhina I.B., Mar'in A.A., Khadzi V.E. (1992) Rose quartz and aventurine synthesis. Razvedka I Okhrana Nedr, Vol. 9, pp. 10-11 (in Russian).

Maschmeyer D., Lehmann G. (1983) A trapped-hole center causing rose coloration of natural quartz. Zeitschrift fur Kristallographie, Vol. 163, pp. 181-196.

Rossman G.R. (1988) Vibrational spectroscopy of hydrous components. In F.C. Hawthorne, Ed., Spectroscopic Methods in Mineralogy and Geology, Mineralogical Society of America, Reviews in Mineralogy, Vol. 18, Chap. 6, pp. 193-206.

Rossman G.R. (1994) Colored varieties of the silica minerals. In P.J. Heaney, C.T. Prewitt, G.V. Gibbs, Eds., Silica—Physical Behavior, Geochemistry, and Materials Applications, Mineralogical Society of America, Reviews in Mineralogy, Vol. 29, Chap. 13, pp. 433-467. 